\title{
Unclaimed Prescriptions Requisitioned Through Provider Order Entry
}

\author{
Jeff A. Papke
}

\begin{abstract}
OBJECTIVE: To identify patients' reasons for not claiming their prescriptions and to suggest solutions for reducing or eliminating their noncompliance.

DESIGN: Patient interviews and literature review.

SETTING: Darnall Army Community Hospital, Fort Hood, TX.

PATIENTS: 656 patients with 860 unclaimed prescriptions for the period February 21-March 17, 1997.

RESULTS: The following reasons for not claiming prescriptions were found to be statistically significant: 1) did not know a prescription had been ordered, 2) had drug at home, or 3) forgot the prescription. Those patients under 45 years old had an $18 \%$ forgetfulness rate while those patients over 45 years old had a $0 \%$ forgetfulness rate. At a cost of $\$ 4.99$ for dispensing each unclaimed prescription, failures to claim prescriptions resulted in $\$ 4,291$ of wasted resources during the study period. If projected for the year, this cost of unclaimed provider order entry (POE) prescriptions would total $\$ 62,654$.
\end{abstract}

CONCLUSIONS: The most common reasons for not claiming the POE prescriptions suggest the need for better communication between providers and patients as the key to improving compliance. Providers need to be educated about the importance of telling their patients when they have entered a prescription order. Patients need to be educated about the POE process and told of the pharmacy policy regarding how long the prescriptions will be held for pickup. Other possible solutions for lowering the current noncompliance rate at Darnall Army Community Hospital would be to implement a Discharge Medication Program that delivers prescriptions to the ward prior to a patient's discharge and to establish a telephone notification system that reminds patients to pick up their prescriptions.

KEYWORDS: Noncompliant patients, Provider order entry, Unclaimed prescriptions.

J Managed Care Pharm 1999: 498-502
JEFF A. PAPKE, M.H.A., is a Health System Administrator, Managed Care Division, Darnall Army Community Hospital, Fort Hood, TX.

ACKNOWLEDGEMENT: The author wishes to thank Nancy Small, Pharm.D., B.C.PS., for her assistance in editing this report for publication.

AUTHOR CORRESPONDENCE: Jeff Papke, M.H.A., Darnall Army Community Hospital, Attn: MCXI-MCD, 36000 Darnall Loop, Fort Hood, TX 76544-4752.

Copyright 191999 Academy of Managed Care Pharmacy, Inc. All rights reserved.
$\mathrm{D}$ arnall Army Community Hospital (DACH) is the largest medical facility within the Department of the Army. Each day, the hospital's main outpatient pharmacy and its five satellite pharmacies fill approximately 3,300 prescriptions. Nearly 800 of these prescriptions are placed and filled during weekdays under provider order entry (POE) at the main outpatient pharmacy via the military's Composite Health Care System (CHCS). The CHCS is a comprehensive medical computer system that integrates inpatient wards, clinical services, administrative departments, and outpatient clinics. ${ }^{1}$ In January 1996, DACH began POE that provided the first link between the hospital's providers and outpatient pharmacies. When a patient seeks medical care and is prescribed medication, the provider directly enters the prescription into the CHCS. The prescription is filled at the pharmacy for pickup by the patient.

Unclaimed prescriptions are returned to stock five days after they are filled. Since DACH's pharmacies began using POE, the chief of pharmacy service estimates that approximately 30 prescriptions per 1,000 filled, or $3 \%$, remained unclaimed. The failure to claim a prescription is due to reasons other than cost and convenience to the patient because all dispensed prescriptions are free and the main outpatient pharmacy is located in the same building in which most patients have sought care.

Throughout the health care system, unclaimed prescriptions result in wasted time and resources for the provider, the pharmacist, and for the organization. The monetary loss due to noncompliance in the United States has been estimated at $\$ 100$ billion per year. ${ }^{2}$ Ultimately, patients may suffer the most for their noncompliance. Approximately 125,000 Americans 
die each year because of noncompliance, which also may result in 5\%-10\% of all hospital admissions. ${ }^{3}$ A $5.5 \%$ hospitalization rate equals 1.94 million admissions per year at a cost of $\$ 8.5$ billion. ${ }^{4}$ Improving patient compliance to ensure optimal patient care and reduce costs is an important goal of the entire health system, particularly of pharmacies.

\section{STATEMENT OF THE PROBLEM}

Although much research on prescription noncompliance has been conducted, relatively little has been done in the new area of unclaimed POE prescriptions. Identifying the monetary amount of wasted resources is important and will be briefly examined; however, this study was conducted primarily to review noncompliant patient records in the CHCS and to interview a representative sample of patients by telephone. This study seeks to: 1) describe a noncompliant patient by demographics; 2) discover those patients' specific reasons for noncompliance; 3) relate unclaimed prescriptions to categories of drugs and clinic type; and 4) discover ways of improving patient compliance.

By gathering this information, the hospital may be better positioned to educate its patients and providers and to improve communication between them. Discovering the types of medicines that go unclaimed and learning patients' reasons for not claiming them could lead to reducing and possibly eliminating unclaimed prescriptions.

\section{METHODS \\ Study sample}

All unclaimed new prescriptions filled under POE from February 21 to March 17, 1997, were examined at the main outpatient pharmacy. New prescriptions are those that had not been previously entered into the pharmacy's CHCS. The telephone survey sample comprised patients who had unclaimed prescriptions during this period. Three attempts were made to contact the noncompliant patient.

\section{Data collection}

The CHCS was examined for noncompliant patients to obtain drug names, patient names, clinic, gender, age, patient classification (active duty, dependents of active duty, retirees, and dependents of retirees), and rank. The following drug and disease categories were used to group unclaimed prescriptions: 1) antiinflammatories, analgesics, and antipyretics, 2) antibiotics, 3) asthma, 4) diabetes, 5) prenatal/postnatal/oral contraceptives, 6) gastrointestinal agents, 7) cardiovascular agents, 8) topicals, and 9) other drugs.

Patients identified as noncompliant were interviewed by telephone during a six-week period. Interviewers asked patients whether they knew they had prescriptions that had not been picked up, the purpose of their physician visits (acute or chronic), and the reasons for not picking up their prescriptions. They also were asked whether their providers told them where to pick up the prescriptions and that their prescriptions would be available for pickup for only five days. Strict confidentiality of patient identification was maintained. All questions were worded so as to elicit a yes or no response for ease of coding

\section{Data analysis}

Demographic data gathered from patient interviews and the CHCS were entered into a personal computer using the Statistical Package for Social Sciences (SPSS) for analysis. All variables were binary except for "age" and "other reason." The predetermined list of reasons for not picking up a prescription is listed in Table 1. Table 2 lists "other reasons" for unclaimed prescriptions. A Chi-square test was conducted to determine whether the difference in forgetfulness rates between patients over and under 45 years of age was significant. A one-sample Chi-square test was used to test null hypotheses for whether the patient forgot to pick up the prescription, had the drug at home, and knew the prescription had been ordered. Expected values were entered into the SPSS program based on earlier findings from literature reviews. ${ }^{5.6}$ The a priori level of significance was set at 0.05 for both types of tests. Table 1 lists the descriptive statistics of all variables.

The costs of dispensing were calculated using Russie's formula that includes all the components that determine the final monetary value of a prescription (personnel salaries, container costs, rent, and utilities). ${ }^{7}$ At DACH, total cost of dispensing is $\$ 4.99$ and includes the time required to fill a prescription and place it on the shelf, verify unclaimed prescriptions against the patient record in the CHCS, log unclaimed prescriptions in the $\mathrm{CHCS}$, and return unclaimed prescriptions to stock when possible. The average number of unclaimed prescriptions per day multiplied by the costs of dispensing multiplied by 365 resulted in the yearly monetary figure of wasted resources.

\section{Results}

During the data collection period, 18,233 prescriptions were filled under POE-a daily average of 730 . Of the total prescriptions, 860 prescriptions for 656 patients were logged into the CHCS as unclaimed-an average of 34.4 unclaimed prescriptions per day for the study period ( $860 / 25$ days). The average rate of $4.72 \%(47.2$ per $1000[860 / 18,233]$ prescriptions filled) was higher than prestudy estimates. Successful telephone interviews were conducted with $40 \%$ of the 656 patients (263/656); 103 of those interviewed were men and 160 were women.

Patients interviewed could give more than one reason for not claiming their prescriptions. Of the patients interviewed, $66 \%$ were not aware that they had unclaimed prescriptions. Thirty percent responded that they were never told where to pick up the prescriptions, and $81 \%$ claimed that they were unaware of the pharmacy's policy of holding prescriptions for only five days for pickup.

One purpose of this study was to identify those noncompliant patients. In this study, $61 \%$ of the noncompliant 
Table 1. Means, Standard Deviations, and Percents of Persons With Unclaimed Prescriptions

\begin{tabular}{|c|c|c|c|c|}
\hline Variable & Mean & S.D. & $\mathrm{n}$ & Percent \\
\hline No. of Unclaimed scripts & 1.43 & 0.930 & 376 & \\
\hline $\begin{array}{l}\text { Gender } \\
\text { Male } \\
\text { Female } \\
\text { Total }\end{array}$ & & & $\begin{array}{l}103 \\
160 \\
263\end{array}$ & $\begin{array}{r}39.0 \\
61.0 \\
100.0\end{array}$ \\
\hline Age & 28.43 & 16.369 & & \\
\hline $\begin{array}{l}\text { Status } \\
\text { Active duty } \\
\text { Dependent of active duty } \\
\text { Retiree } \\
\text { Dependent of retiree } \\
\text { Other } \\
\text { Total }\end{array}$ & & & $\begin{array}{r}109 \\
115 \\
12 \\
24 \\
3 \\
263\end{array}$ & $\begin{array}{r}41.5 \\
43.7 \\
4.6 \\
9.1 \\
1.1 \\
100.0\end{array}$ \\
\hline $\begin{array}{l}\text { Rank } \\
\text { El-E4 } \\
\text { E5-E6 } \\
\text { E7-E9 } \\
\text { O1-O3 } \\
\text { O4-O6 } \\
\text { O7-O9 } \\
\text { WOl-WO5 } \\
\text { No rank } \\
\text { Total }\end{array}$ & & & $\begin{array}{r}66 \\
17 \\
16 \\
3 \\
5 \\
0 \\
3 \\
153 \\
263\end{array}$ & $\begin{array}{r}25.1 \\
6.5 \\
6.1 \\
1.1 \\
1.9 \\
0.0 \\
1.1 \\
58.2 \\
100.0\end{array}$ \\
\hline $\begin{array}{l}\text { Drug/Disease State Category' } \\
\text { Antiinflammatories/analgesics/antipyretics } \\
\text { Pre \& Postnata/Oral contraceptives } \\
\text { Antibiotics } \\
\text { Cough \& cold remedies } \\
\text { Hypertension/heart disease } \\
\text { Gastrointestinal agents } \\
\text { Asthma } \\
\text { Diabetes control } \\
\text { Topicals } \\
\text { Other. } \\
\text { Total }\end{array}$ & . & & $\begin{array}{r}72 \\
47 \\
16 \\
26 \\
9 \\
26 \\
4 \\
2 \\
28 \\
85 \\
315\end{array}$ & $\begin{array}{r}27.4 \\
17.9 \\
6.1 \\
9.9 \\
3.4 \\
9.9 \\
1.4 \\
8.0 \\
10.6 \\
32.3 \\
119.7\end{array}$ \\
\hline $\begin{array}{l}\text { Clinic/Department }^{2} \\
\text { Dental clinic } \\
\text { Psychiatry } \\
\text { Pediatrics } \\
\text { Ambulatory clinics } \\
\text { Emergency department } \\
\text { OB/GYN clinic } \\
\text { Medicine department } \\
\text { Surgical department } \\
\text { Troop medical clinic (TMC) } \\
\text { Total }\end{array}$ & & & $\begin{array}{r}13 \\
8 \\
11 \\
33 \\
45 \\
64 \\
43 \\
13 \\
34 \\
264\end{array}$ & $\begin{array}{r}4.9 \\
3.0 \\
4.2 \\
12.5 \\
17.1 \\
40.0 \\
16.3 \\
4.9 \\
12.9 \\
116.8\end{array}$ \\
\hline $\begin{array}{l}\text { Aware That Script Had Not Been Claimed } \\
\text { Yes } \\
\text { No } \\
\text { Total }\end{array}$ & & & $\begin{array}{r}89 \\
174 \\
263\end{array}$ & $\begin{array}{r}33.8 \\
66.2 \\
100\end{array}$ \\
\hline $\begin{array}{l}\text { Purpose of Visit } \\
\text { Acute condition } \\
\text { Chronic condition } \\
\text { Routine visit (e.g. physical exam) } \\
\text { Total }\end{array}$ & & & $\begin{array}{r}144 \\
78 \\
41 \\
263\end{array}$ & $\begin{array}{r}54.8 \\
29.6 \\
15.6 \\
100\end{array}$ \\
\hline $\begin{array}{l}\text { Provider Said Where To Pick Up Script } \\
\text { Yes } \\
\text { No } \\
\text { Total }\end{array}$ & & & $\begin{array}{r}183 \\
80 \\
263\end{array}$ & $\begin{array}{r}69.6 \\
30.4 \\
100.0\end{array}$ \\
\hline $\begin{array}{l}\text { Aware of Five Day Pharmacy Policy } \\
\text { Yes } \\
\text { No } \\
\text { Total }\end{array}$ & & & $\begin{array}{r}51 \\
212 \\
263\end{array}$ & $\begin{array}{r}19.4 \\
.80 .6 \\
100.0\end{array}$ \\
\hline $\begin{array}{l}\text { Reason for not picking up script } \\
\text { Forgot } \\
\text { Afraid of adverse reaction } \\
\text { Had medicine at home } \\
\text { Inconvenient to use } \\
\text { Wait in pharmacy too long } \\
\text { Did not know prescription was ordered } \\
\text { Other } \\
\text { Total }\end{array}$ & & & $\begin{array}{r}40 \\
6 \\
48 \\
1 \\
29 \\
72 \\
98 \\
294\end{array}$ & $\begin{array}{r}15.2 \\
23.0 \\
18.3 \\
0.4 \\
11.1 \\
27.4 \\
37.3 \\
112.0\end{array}$ \\
\hline
\end{tabular}

patients were women. Forty-two percent were active-duty soldiers, and $44 \%$ were dependents of active-duty soldiers; their average age was 28.4 . Approximately $76 \%$ of the interviewed patients fell between the ages of 11 and 46 .

The following reasons for not claiming prescriptions were identified from the predetermined list of reasons: 72 patients did not know a prescription had been ordered (27.4\%), 48 patients had some of the medicine at home (18.3\%), 40 patients forgot the prescription (15.2\%), and 29 patients thought the wait in the pharmacy was too long $(11.1 \%)$. Of 98 patients $(37.3 \%)$ who gave reasons that fell under the general category "other," 18 believed they did not need the medication; 11 said the particular prescriptions were not with the other prescriptions they picked up; eight expected a written order; seven had no time to pick up their prescriptions; six went out of town; five said the pharmacy was closed; and four thought that the prescription would make them sick.

The third purpose of this study was to identify clinics and departments representing unclaimed prescriptions and the type of medicines most often left unclaimed. The top five unclaimed prescriptions according to drug type were antiinflammatories (27.4\%); prenatal and postnatal medications or oral contraceptives (17.9\%); topicals (10.6\%); cough and cold remedies $(9.9 \%)$, and gastrointestinal agents $(9.9 \%)$. The top five clinics or departments having unclaimed prescriptions were Obstetrics/Gynocology (24.3\%), the Emergency Department (17.1\%), the Department of Medicine (16.3\%), Troop Medical Clinics (12.9\%), and Ambulatory Clinics (12.5\%).

Two age groups were examined from the survey population-those under 45 years and those over 45 . Overall, the 263 patients had a $15 \%$ forgetfulness rate; those over 45 had a rate of $0 \%$, while those under 45 had a rate of $18 \%$. A Chisquare test revealed a statistically significant difference in rates with (263) $\chi^{2}(1)=7.72, \mathrm{p}<0.01$. Pearson's $r$ correlation of -0.1714 between these two variables indicates an inverse relationship between the patients' age and their tendency to forget their prescriptions.

In one published study, $38 \%$ of surveyed patients cited forgetfulness as a reason for not claiming their prescriptions, ${ }^{5}$ while only $15 \%$ of the patients in this study cited forgetfulness as the reason for their noncompliance. A Chi-square test revealed a statistically significant difference with (263) $\chi^{2}$ $(1)=57.98, p<0.001$ meaning. DACH expected 100 persons to claim forgetfulness as a reason (actual $=40$ ). A comparison of this study with the previous report indicates that forgetfulness is not a statistically significant reason for not claiming a prescription. Thirty-five percent of the patients in the published study claimed they already had the drug at home, while the DACH study observed that the number of these cases was 48 , or $18.3 \%$. These results were considered statistically significant with (263) $\chi^{2}(1)=32.43, \mathrm{p}<0.001$. Another previous study reported $5.7 \%$ of the surveyed patients did not know that a prescription had been ordered for them compared with $27 \%$ in the $\mathrm{DACH}$ study. ${ }^{6}$ These results were considered significant with $(263) \chi^{2}(1)=229.90, p<0.001$. 
During the data collection period, 860 prescriptions representing $\$ 4,291.40$ went unclaimed. Because the pharmacy is open every day, projecting unclaimed prescriptions throughout the year would result in approximately $\$ 62,654.44$ (34.4 prescriptions/day x $365 \times \$ 4.99$ ) in wasted resources.

\section{Discussion}

A literature review indicated $38 \%$ of the noncompliant patients cited forgetfulness as a reason..$^{5}$ In one study the authors speculated that the forgetfulness may have been semipurposeful, which may be the case in this study as well.

The results of the telephone survey indicate that several solutions could be implemented to improve patient compliance. A telephone notification system could be used to call patients at home to remind them to pick up their prescriptions. This proposed system should target the younger age group $(<45)$ due to their higher rate of forgetfulness. Another study reported $35.7 \%$ of the patients contacted by phone picked up their prescriptions. ${ }^{6}$ Although that percentage may be somewhat low, applying the $35.7 \%$ success rate to this study would have resulted in another 234 patients claiming their prescriptions ( $35.7 \% \times 656$ ) for a savings of $\$ 1,669.75$ $\chi^{2} 34 \times 1.43$ prescriptions/patient $\times \$ 4.99$ cost of dispensing). Telephone notification could have lowered the noncompliance rate from $4.72 \%$ to $2.88 \%$.

Ireland Army Community Hospital was the site of an earlier report on unclaimed prescriptions. ${ }^{8}$ As part of that study, clinics were identified by their respective number of unclaimed prescriptions. A statistical difference in rates éxists between $\mathrm{DACH}(40 \%)$ and Ireland (21.4\%) for unclaimed prescriptions originating from Obstetrics/Gynocology with $\chi^{2}(1)=32.91$, $\mathrm{p}<0.001$. DACH averages eight births per day. Many of the unclaimed prescriptions were for oral contraceptives, condoms, vaginal foam, and vitamins prescribed following the birth of a child. The latter prescription is usually given to new mothers at discharge. Because there are many steps involved in a discharge, patients may not be expected to remember their prescriptions before going home. A discharge medication program that enables prescriptions to be delivered to the patient on the ward could significantly improve compliance in this category. In addition, patient satisfaction could be improved, because the patient's schedule on discharge day is already hectic.

Education and communication are the main solutions for reducing or eliminating unclaimed prescriptions. High rates of patients report that they did not know where to pick up their prescriptions and did not know that a prescription had been ordered for them. This illustrates the need for solutions. Each clinical department must ensure that its patients are told about the POE prescription process. At Walter Reed Army Medical Center, a 13\% drop in unclaimed antibiotic prescriptions was reported when physicians were told to emphasize to patients the date prescriptions were being written. ${ }^{9}$ Research shows the number of unclaimed prescriptions drops when they are held longer than five days, which indicates that a longer holding period could also offer a partial solution. ${ }^{10}$

\section{Table 2. Reasons for Unclaimed Prescriptions}

\section{Reason}

Frequency

Felt they didn't need it $\ldots \ldots \ldots \ldots \ldots \ldots \ldots \ldots$

Not in bag with other prescriptions $\ldots \ldots \ldots \ldots \ldots \ldots \ldots 11$

Expected a written prescription $\ldots \ldots \ldots \ldots \ldots \ldots \ldots .$.

No time to pick up prescription $\ldots \ldots \ldots \ldots \ldots \ldots . \ldots 7$

Patient went out of town $\ldots \ldots \ldots \ldots \ldots \ldots \ldots$

Pharmacy was closing or closed . . . . . . . . . . . . 5

Told provider the prescription made them sick ......... 4

Getting prepped for surgery $\ldots \ldots \ldots \ldots \ldots \ldots \ldots \ldots . \ldots \ldots$

Second provider said to not take the prescription $\ldots \ldots \ldots \ldots 2$

Pharmacy did not carry particular medicine $\ldots \ldots \ldots \ldots .2$

Patient did not have ID card $\ldots \ldots \ldots \ldots \ldots \ldots \ldots \ldots \ldots .2$

Patient had no transportation to DACH pharmacy ......... 2

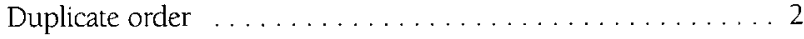

Quantity mistake on pharmacy's part $\ldots \ldots \ldots \ldots \ldots \ldots .2$

Original prescription substituted by pharmacy $\ldots \ldots \ldots \ldots 2$

Provider prescribed medicine for wrong reasons . . . . . . . . 1

Daughter could not wait for mother to get prescription $\ldots \ldots$ l

Neglected to pick it up $\ldots \ldots \ldots \ldots \ldots \ldots \ldots \ldots \ldots \ldots$

Rudeness of pharmacist $\ldots \ldots \ldots \ldots \ldots \ldots \ldots \ldots \ldots$

Small quantity was not worth effort $\ldots \ldots \ldots \ldots \ldots \ldots \ldots . . \ldots$

Understood prescription to be ordered later .............

Prescription was picked up at Killeen FCC's pharmacy $\quad \ldots \ldots$.

Thought prescription was available anytime $\ldots \ldots \ldots \ldots \ldots 1$

Provider changed mind about prescription $\ldots \ldots \ldots \ldots \ldots \ldots 1$

Prescription was ordered after patient left DACH $\ldots \ldots \ldots \ldots 1$

Given to patient by pharmacist after hours . . . . . . . . . .

Two separate providers ordered same prescription .........

Received prescription direct from another clinic . . . . . . . . . .

Patient had another form of Tylenol at home $\ldots \ldots \ldots \ldots \ldots$.

Felt prescription might interfere with job performance . . . . . . l

Did not like medication's side effects . . . . . . . . . . . . . .

Had access to prescription at own battalion aid station . . . . . . .

Patient picks up all medications at end of month . . . . . . . .

Prescription not available for pickup by patient $\ldots \ldots \ldots \ldots .1$

Inconvenient to go to main DACH pharmacy .............

Pediatrics pharmacy closed-sent to main pharmacy .........

Did not know where pharmacy was located . . . . . . . . . . .

Pharmacy was out of the particular prescription . . . . . . . . .

Total . . . . . . . . . . . . . . . . . . . 98

Eighteen patients reported they did not need the prescriptions, a fact that should lead providers to ensure that their patients comply with the prescription order. This practice would help involve the patients more directly in their own care. Improving the communication flow is essential for improving compliance and reducing the amount of wasted resources. If providers discover that patients already have adequate supplies of medicine at home, they should not place POE prescriptions. The practice of ordering a prescription so it will be there when needed is not appropriate.

Information concerning the pharmacy's policy on how long they will hold prescriptions for pickup needs to be disseminated throughout the community and hospital. Almost $81 \%$ of those interviewed reported that their providers did not tell them 
about this policy. A search for an effective method for educating patients on pharmacy procedures, the risks of noncompliance, and the costs of unclaimed prescriptions should be initiated.

Although a paperless system like the POE process is considered ideal, many patients prefer having something in hand to remind them of their prescriptions. A patient's lack of involvement in the prescription-transmittal process most likely increases noncompliance. The CHCS has the ability to give the patient a Patient Order Sheet to present at the pharmacy.

Several patients reported that the pharmacy was at or near closing when they tried to claim their prescriptions and others reported that they had no time to pick up their prescriptions. Because the main outpatient pharmacy is open seven days a week for a total of 86 hours, extending pharmacy hours is clearly not the solution. The POE system exists in part to save the patient time. Also, priority service is given to patients with POE prescriptions. Computer records from the CHCS show that the average waiting time for POE prescriptions was 10.6 minutes during the study period. These findings seem to contradict patients' complaints about long waits and having problems with time and access to the pharmacy. Again, educating the providers and patients and improving the communication process between these groups would enhance patient compliance.

\section{CONCLUSION}

POE is a relatively new method for processing prescriptions. Its many benefits include saving money and time-the provider's, the pharmacist's, and, most important, the patient's. POE also enables the pharmacist to check the patient's drug profile for interactions. POE enables the pharmacist to spend quality time with the patient, which results in greater customer satisfaction. POE systems are beginning to expand to other managed care systems. These systems likely will present similar and possibly even greater challenges as the populations served expand beyond the limited population in this study. In other managed care systems, not all involved parties may be at a centralized location; patients will have the option of choosing among different pharmacies.

To make POE systems work effectively for all involved, providers must emphasize the importance of adhering to the prescribed therapy. The providers also must confirm that patients understand how and where to obtain prescriptions. Pharmacists must communicate how long POE prescriptions are held and must remind patients to pick them up. The last link in this process is that of a user-friendly computer system capable of supporting POE efforts. Any lapse in these three areas results in noncompliance and unclaimed prescriptions.

Although eliminating all unclaimed prescriptions is a worthy goal, it is simply not realistic. However, reducing unclaimed prescriptions is meaningful and should contribute to the improved health of the population served. In addition, reducing noncompliance should help conserve limited resources. Some costs, such as those for increased lengths of stay, expanded procedures or treatments, and repeated clinic visits are not easily quantified in examining noncompliance; however, noncompliance could have a negative impact on a patient's health. The importance of provider and patient interaction and communication cannot be overstated. As with any new product or system, education and communication are crucial to ensuring the success of POE.

\section{References}

1. Hubbell PJ. The pharmacy as part of an integrated hospital information system: a focus on benefits. Hospital Pharmacy. 1994; 29: 440-41, 445-46, 468.

2. Donovan JL. Patient decision making: the missing ingredient in compliance research. International Journal of Technology Assessment in Health Care. 1995; 11: 443-55.

3. McCaffrey DJ. Why prescriptions go unclaimed. US Pharmacist. 1993; 8: $58,60,62,64-65$.

4. McNally DL, Wertheimer DM. Strategies to reduce the high cost of patient noncompliance. Maryland Med J 1992; 41: 223-25

5. Schering Report XVIII. The phantom patient and community pharmacy practice. A report by Schering Laboratories. Kenilworth, NJ, 1996.

6. Hamilton WR, Hopkins UK. Survey on unclaimed prescriptions in a community pharmacy. J Amer Pharm Assoc 1997; NS37: 341-45.

7. Russie, G. Researching the components of prescription pricing in a military pharmacy [dissertation]. Austin, TX: University of Texas, 1996.

8. Craghead RM, Wartski DM. An evaluative study of unclaimed prescriptions. Hospital Pharmacy. 1991; 26: 616-17, 632 .

9. Carlson RH. Study identifies patients least likely to pick up prescriptions from outpatient pharmacy. Pharmacy Practice News 1997; 24: 44-45.

10. Kirking $\mathrm{MH}$, Kirking DM. Evaluation of unclaimed prescriptions in an ambulatory care pharmacy. Hospital Pharmacy. 1993; 28: 90-91, 94, 102. 